\title{
Valoração Médico-Pericial do Dano Estético
}

\section{Medical-Examiner Assessment of Aesthetic Damages}

\author{
Lucas Pedroso Fernandes Ferreira Leal ${ }^{1}$, Élcio Rodrigues da Silva ${ }^{2}$, Viviam \\ Paula Lucianelli Spina ${ }^{3}$, Jonas Aparecido Borracini ${ }^{4}$, Fábio Tadeu Panza ${ }^{5}$
}

DOI: http://dx.doi.org/10.11606/issn.2317-2770.v22i1p41-49

\begin{abstract}
Leal LPFF, Silva ER, Spina VPL, Borracini JA, Panza FT. Valoração Médico-Pericial do Dano Estético. Saúde, Ética \& Justiça. 2017;22(1):41-9.

RESUMO: O exame pericial de avaliação de danos constitui uma atividade técnica, à qual se aplicam as regras da Arte Médica, considerando-se o âmbito do Direito em que se insere. O laudo médico deve ser completo e fazer compreender a situação real do indivíduo. A avaliação do experto deve assegurar o esclarecimento do juízo, contribuindo para que se promova a Justiça. É fundamental que o dano pessoal seja identificado, descrito e valorado de acordo com rigoroso método científico. Este artigo discorre sobre o Dano Estético e reflete a experiência do Instituto de Medicina Social e de Criminologia do Estado de São Paulo (IMESC) tanto em seu diagnóstico quanto em sua valoração dentro do arcabouço legal brasileiro, de acordo com método de avaliação baseado em escala quantitativa-descritiva, buscando-se harmonização em sua ponderação, dentro do princípio geral da reparação integral dos danos, de modo contextualizado e fundamentado.
\end{abstract}

DESCRITORES: Prova Pericial; Metodologias de Avaliação de Danos; Estética; Medicina Legal; Indenização.

\footnotetext{
1. Médico Diretor do Departamento de Estudos e Perícias do Instituto de Medicina Social e de Criminologia do Estado de São Paulo (IMESC), Doutor em Ciências pela Universidade Federal de São Paulo - UNIFESP, Especialista em Medicina Legal e Perícias Médicas, Especialista em Cirurgia Geral, Pós-graduado em Medicina Legal e Perícias Médicas pela Faculdade de Ciências Médicas da Santa Casa de Misericórdia de São Paulo - FCMSCSP, Pós-Graduado em Avaliação do Dano Corporal Pós-Traumático pela Universidade de Coimbra - INML, Perito Oficial do IMESC, Presidente da Comissão Interdisciplinar de Perícias Indiretas do IMESC, Ex-Médico-Legista do Instituto Médico-Legal do Núcleo de Santos da Superintendência da Polícia Técnico-Científica.

2. Médico Diretor do Centro de Perícias do Instituto de Medicina Social e de Criminologia do Estado de São Paulo (IMESC), Especialista em Medicina Legal e Perícias Médicas, Especialista em Cardiologia, Perito Oficial do IMESC.

3. Médica Perita Oficial do Instituto de Medicina Social e de Criminologia do Estado de São Paulo (IMESC), Mestre em Ciências pela Universidade Federal São Paulo, Especialista em Medicina Legal e Perícias Médicas, Especialista em Ginecologia e Obstetrícia, Pós-graduada em Medicina Legal e Perícias Médicas pela Faculdade de Ciências Médicas da Santa Casa de Misericórdia de São Paulo - FCMSCSP, Pós-Graduada em Avaliação do Dano Corporal Pós-Traumático pela Universidade de Coimbra - INML.

4. Médico Diretor do Núcleo de Perícias Clínicas do Instituto de Medicina Social e Criminologia do Estado de São Paulo (IMESC), Especialista em Ortopedia e Traumatologia pela Sociedade Brasileira de Ortopedia e Traumatologia, Especialista em Patologias do Quadril pela Sociedade Brasileira de Quadril, Especialista em Medicina Legal e Perícias Médicas, Perito Oficial do IMESC.

5. Médico Perito Oficial do Instituto de Medicina Social e de Criminologia do Estado de São Paulo (IMESC), Mestre e Especialista em Cirurgia Geral, Pós-Graduado em Avaliação do Dano Corporal Pós-Traumático pela Universidade de Coimbra - INML.

Endereço para correspondência: Lucas Pedroso Fernandes Ferreira Leal. E-mail: lucaslealdr@uol.com.br
} 


\section{INTRODUÇÃO}

$\mathbf{N}$

o âmbito da avaliação de danos corporais, em todos os quadros jurídicos, a prova pericial é essencialmente médica ${ }^{1}$. O laudo médico-legal deve atender às normas específicas de forma a satisfazer cabalmente os objetivos a que se destina, conforme o âmbito do Direito em que tem $\operatorname{lugar}^{1,2}$. Apresenta-se sob a forma de um relatório em que se descreve o resultado dos exames efetuados e se interpretam esses dados, elaborando-se um conjunto de conclusões devidamente fundamentadas. A função do perito é saber dar resposta ao objetivo da perícia, procurando traduzir a complexidade da avaliação técnica por palavras simples, para que os magistrados possam apreciar os resultados exarados sobre bases concretas ${ }^{1}$, com vistas a auxiliar na formação de seu entendimento e na fundamentação de sua decisão ${ }^{2}$.

A identificação do dano está relacionada com o diagnóstico, que é firmado com base em princípios propedêuticos consagrados, e sua valorização deve ser apurada. Temos observado, e criticado, a forma simplista de parte dos relatórios médico-legais em ações indenizatórias, tão somente dispondo de análise da capacidade laborativa e informação de um "percentual de indenização", na maior parte das vezes baseado na Tabela de Indenização Securitária da SUSEP (Superintendência de Seguros Privados), como se assim se traduzissem todos os aspectos relacionados ao dano e como se isso espelhasse o comprometimento do potencial de trabalho do indivíduo. A apuração do dano respeita critérios científicos, é ciência, e como tal dever ser reprodutível, precisa e compreensível. Na avaliação do dano corporal de natureza cível, contemplam-se os danos temporários e permanentes, patrimoniais e não-patrimoniais, dentro do princípio geral da reparação integral dos danos ${ }^{1,3}$, de modo objetivo e fundamentado.

No Direito Civil, o laudo médico deve ser completo para se fazer compreender a situação real do indivíduo, mediante análise de todos os parâmetros de dano, o que permitirá estabelecer e assegurar o montante indenizatório ${ }^{1}$. É fundamental que se identifique, descreva e avalie a totalidade do dano, com suas repercussões em todos os níveis, traduzindo-as e valorizando-as através de método científico, de acordo com lex artis. Não há, no Brasil, normatização relativa a critérios para a reparação do dano a ser seguida e ditada por Sociedades Médicas, Instituições e nem há Legislação Específica, com detalhado critério analítico relativo à repercussão do dano. Há necessidade de uniformização de critérios a serem utilizados, baseados em conceitos de consenso científico, tendo em conta que o exame pericial de avaliação de danos corporais constitui uma atividade técnica.

Atrelados a este objetivo, e para estar em consonância com a norma jurídica, esmiuçamos as características determinantes na configuração e na ponderação do dano estético em demandas indenizatórias, tendo em conta critérios técnicos de amplo foco analítico, para melhor oferecer informações ao Magistrado e auxiliá-lo em seu julgamento, uma vez que o relatório médico-legal possui, em termos probatórios, um valor particularmente relevante ${ }^{2}$. Cabe promover a harmonização de procedimentos e de avaliações para situações similares, respeitando-se metodologias periciais em vigor, o princípio da equidade e a justiça social. A particularização da repercussão global do dano em cada indivíduo, no seu contexto de vida (e não só no trabalho), na análise das perdas, privações e desvantagens que possam ter advindo do dano, propicia um detalhado conjunto de informações para que o Magistrado tenha condição de reparar o dano e o sofrimento físico-psíquico do indivíduo.

Ultrapassada a análise do evento traumático e da ponderação técnica do nexo de causalidade entre o dano corporal apresentado e o evento em tela, determina-se a data de cura ou de consolidação médico-legal das lesões ${ }^{3}$. Conceitualmente, a valoração de danos é dividida em danos temporários e danos permanentes. A consolidação é o momento em que, na sequência de um período transitório que constituiu a fase de danos temporários, se constata que as lesões deixaram de sofrer uma evolução regular observável, seja por terem estabilizado definitivamente, seja por não serem susceptíveis de sofrer modificações, não sendo necessários mais tratamentos a não ser para evitar um agravamento, não se vislumbrando qualquer melhora apreciável, e em que é possível observar um determinado grau de afectação da integridade físicopsíquica $^{1,3}$. A partir do momento em que se admite que ocorreu a consolidação médico-legal da lesão, tem-se que o prejuízo adquiriu um caráter permanente, não sendo mais susceptível de alterações significativas, a não ser, eventualmente, no decurso de um período muito extenso (de anos ou décadas) não perspectivável no momento ${ }^{1}$. A avaliação das consequências do dano sofrido, tendo-se em mente suas repercussões, se dá conforme parâmetros de dano estabelecidos na Literatura ${ }^{1,3-5}$.

Realizamos revisão especializada e jurídica para firmar conceitos médico-legais no contexto pericial brasileiro, abordando os aspectos técnicos envolvidos na valoração do dano estético. O Instituto de Medicina Social e de Criminologia do Estado de São Paulo (IMESC) tem difundido o conhecimento sobre esse tema pertinente ao meio pericial visando contribuir para a formação e a capacitação profissionais. Isso se faz necessário seja por não se dispor de dispositivo legal que o caracterize explicitamente, seja pela falta de consenso em sua valoração ou mesmo pelo uso indevido de dispositivos que não se prestam para este fim. 


\section{DESENVOLVIMENTO}

Dano Estético corresponde à repercussão permanente das sequelas, numa perspectiva estática e dinâmica, envolvendo uma avaliação personalizada da afetação da imagem do indivíduo, quer em relação a si próprio, quer perante outrém ${ }^{1,3,4}$. As características que o definem devem ser atendidas, para que este parâmetro de dano se converta em prejuízo e seja susceptível de ser indenizado ${ }^{1}$. Há que ser o dano visível à distância íntima, ter caráter permanente e produzir repúdio à harmonia corporal do indivíduo, ponderando-se o conjunto. Devese considerar o seu grau de notoriedade e deterioração, o desgosto manifestado e as privações vivenciadas pela pessoa $^{6}$ e assinalada a sua eventual possibilidade de reparação especializada, designadamente cirúrgica ${ }^{7}$.

ODanoEstéticoétidocomoqualquerirregularidade física ou alteração corporal externa permanente que pressuponha fealdade ostensiva ao ser visualizada ${ }^{1,8,9}$. É entendido como a diminuição da atração estética, deterioração da aparência ou modificação pejorativa que sofre um indivíduo, que lhe cause desgosto ou inferiorizante complexo, perante si e sobre a coletividade, e não exclusivamente a deformidade física que causa aleijão e repugnância. $\mathrm{O}$ termo tem sido reconhecido como o mais apropriado para designar, no campo da responsabilidade civil, as sequelas relativas aos prejuízos da imagem corpora ${ }^{10}$, na aparência externa da pessoa, de forma duradoura e para pior, implicando em redução dos padrões de beleza estabelecidos pela sociedade ou mesmo

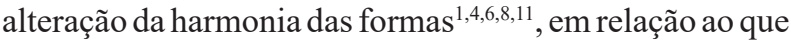
era antes da ocorrência do evento danoso, relativamente aos seus traços naturais e não em comparação a algum exemplo de beleza ${ }^{12}$. Ademais, vale salientar que apenas uma avaliação personalizada permite atender ao princípio da reparação integral do dano.

A boa imagem abrange várias dimensões, como a intelectual, a profissional, a social, a emocional, a física, que formam um só e indivisível conjunto ${ }^{11}$. Se uma dessas partes for afetada, ocorrerá o desequilíbrio da integridade da personalidade, não sendo mais a mesma que era antes do evento danoso ${ }^{13}$. A imagem de uma pessoa é uma construção complexa e multifacetada que segue labirintos cognitivos individualíssimos; é um patrimônio que se valora externamente na relação interpessoal e que pode ter múltiplos objetivos e estabelecer relações emocionais diferentes. Quando a imagem de uma pessoa se altera, pode provocar diferentes danos e, quando isso ocorre, o objetivo prioritário é a sua reparação integral. Quando a restituição total da imagem da pessoa não é conseguida, o causador tem a responsabilidade de 'compensar' as consequências que tal alteração provoca ${ }^{7}$.

Nem toda sequela decorrente de um trauma remeterá a dano estético com possibilidade de valoração e indenização. Caso a deformação estética seja temporária, apresente recuperação substancial, caso possa ser removida ou desapareça em um prazo razoável de tempo, voltando ao seu estado anterior (restituição integral), sem deixar sequela, não há o que se falar em dano estético permanente ${ }^{1,12,13}$. Outrossim, um dano estético temporário poderá ser incluído no âmbito da avaliação do quantum doloris, ponderando-se o sofrimento psíquico que lhe foi decorrente, em casos singulares ${ }^{1}$.

O dano estético não tem previsão própria no ordenamento jurídico brasileiro, clamando por particularização e, assim, reparação plena. Admite-se que existirá sempre que houver alteração do estatuto estético do indivíduo com dignidade suficiente para merecer a tutela do Direito ${ }^{1}$. No âmbito da responsabilidade civil - obrigação que pode incumbir a uma pessoa de reparar o prejuízo causado a outrem por fato seu, ou pelo fato das pessoas ou das coisas dela dependentes, seja contratual ou extracontratual ${ }^{14}$, o dano estético é um dano extrapatrimonial ${ }^{3,12,13,15,16}$, insuscetível de concreta avaliação pecuniária, que não tem expresso conteúdo econômico. Entretanto, o dano estético poderá pontualmente constituir, ou não, um prejuízo patrimonial (designando danos materiais, nos casos em que o indivíduo exerça profissão que exija um bom estatuto estético, pois pode refletir sobre a capacidade laborativa específica e genérica e sobre a capacidade de ganho) $)^{1,3,17}$, além de poder ter virtualidade de danos morais ${ }^{14}$. O que se busca, na verdade, com supedâneo nos artigos $5^{\circ}, 6^{\circ}$ e 196, da Constituição Federal ${ }^{18}$, e nos artigos 186, 187, 927 e 949 do Código Civil ${ }^{19}$, é a garantia do princípio da justa e integral reparação do dano sofrido. A legislação assegura a indenização quando comprovados os danos material, moral ou à imagem ${ }^{13,15,16}$. A plena proteção dos bens juridicamente tutelados é amparada quando de procede à valoração do dano estético, em qualquer gênero de dano que seja juridicamente admitido, não se podendo objetar contra a sua reparação quando se traduz em repercussão de ordem moral, material ou como terceira espécie de dano. Tem-se que a questão patrimonial e extrapatrimonial do dano estético é meramente jurídica, não interferindo diretamente na apreciação médico-legal nem sendo pertinente sua discussão pelo experto.

A evolução histórica do dano estético demonstra que, antigamente, este era absorvido na indenização do dano moral, sendo atrelado a ele, sem suas próprias características, uma vez que englobaria o prejuízo que afeta os ânimos psíquico, moral e intelectual, e a saúde e atributos físicos do indivíduo ${ }^{1,12}$. Já foi também o dano estético considerado como sendo um prejuízo material de ofensa ao patrimônio por poder ser susceptível e necessitar de reparação cirúrgica e outros tratamentos, e por poder afetar a profissão, comprometendo os ganhos habituais do indivíduo ou diminuindo as suas probabilidades de colocação ou de exercício da atividade a que se dedica, além de implicar em outras despesas ${ }^{1,13,16,17}$. 
Com o decorrer do tempo, o dano estético foi ganhando especificidade, distinguindo-se do dano moral, por suas diferenças. $\mathrm{Na}$ atualidade, em países europeus, tem entidade própria, assumindo grande importância o seu sistema de avaliação ${ }^{1}$.

Existe uma grande discussão doutrinária acerca do dano estético ${ }^{12-16}$, pois alguns juristas pensam ser ele uma espécie de dano moral, suprimindo-o, ao passo que outros estudiosos entendem que se trata de uma terceira espécie de dano, autônoma em relação aos outros tipos. Existem tribunais brasileiros que concedem a indenização por dano estético dentro dos danos morais e, outros, em separado ${ }^{8,20,21}$. O dano estético não é sinônimo de dano moral, haja vista que não possuem a mesma natureza e comportam reparação diversa. O dano estético é tido como objetivo, externo, ostensivo, verificável por inspeção física, que desperta a atenção, e está vinculado ao sofrimento pela deformação física permanente ${ }^{22}$, cuja prova se faz mediante contato visual com a vítima, demonstrando-se as diferenças após o acontecimento danoso ${ }^{16}$. Já o dano moral é tido como de ordem subjetiva, interna, encoberto, inerente a cada indivíduo, e está ligado ao sofrimento e a todas as demais consequências nefastas dele advindas, não se exigindo durabilidade ${ }^{22}$, cuja conjunção probatória se dá por meio de depoimento pessoal e testemunhal, o qual confirme que a vítima esteve abalada emocionalmente e/ou constrangida perante a sociedade em razão daquele dano ${ }^{16}$.

A cumulação das indenizações pelos danos moral e estético está assegurada pela súmula 387 do Superior Tribunal de Justiça, do ano de $2009^{12,16,21,23}$, com a comprovação da caracterização de ambos os danos no caso concreto, distinguindo-se com precisão as condições que justifiquem cada um deles, unindo, assim, apenas os valores pecuniários para efeitos de pagamento de indenizações distintas. Não é o caso de se ter ourtogado bis in idem (repetição de uma indenização para o mesmo fato, dupla indenização pelo mesmo dano). Preconiza-se que deva ficar claro e fundamentado no decisório que o valor arbitrado abranja o condizente com a compensação por danos estéticos e morais, ainda que originários do mesmo fato $^{12,14}$. Vale salientar que a questão da autonomia e da cumulação do dano estético não é unânime na doutrina ${ }^{16}$, não se podendo tolher a liberdade do julgador ${ }^{15}$.

Avaliar a extensão do dano estético é matéria de grande dificuldade para um julgador, assim como quantificar qualquer dano extrapatrimonial ${ }^{13}$, não havendo disciplina de sua liquidação nem tampouco parâmetros básicos para evitar decisões díspares ${ }^{24}$. Contudo, não se podem olvidar diversas nuances para estabelecer o valor da indenização desta espécie de dano ${ }^{15}$. Não sendo o dano estético auferível pecuniariamente, sua reparação trata-se, na realidade, de uma compensação satisfatória, cujo valor deve ser arbitrado segundo os critérios da razoabilidade e da proporcionalidade, levados em consideração os aspectos conjunturais e a extensão do dano perpetrado ${ }^{13,15}$; não deve ser irrisório, tampouco fonte de enriquecimento sem causa e injustificável, cabendo assim ser o ressarcimento condizente com a realidade, amenizando o sofrimento do ofendido, exercendo função reparadora do prejuízo e de prevenção da reincidência da conduta lesiva. A finalidade precípua da reparação do dano estético é obter compensação pelos prejuízos que lhe são inerentes, sem detrimento da obtenção de indenização por dano moral e material ${ }^{16}$.

Tradicionalmente, dentre os fatores levados em conta para a quantificação indenizatória em ação que trate do dano estético, têm-se ${ }^{13,15,25}$ : a extensão e a localização do dano, a gravidade e intensidade da ofensa, o sofrimento do indivíduo, as suas condições pessoais da vítima, o grau de culpabilidade do agente, a repercussão do fato danoso, e as condições socioeconômicas do ofensor e do ofendido. Os aspectos delineados elidem qualquer espécie de indenização tarifada e taxativa no que tange à reparação do dano estético ${ }^{15}$. Concluindo pela autonomia e independência dos danos material, moral e estético, o juiz arbitrará o quantum devido separando as verbas relativas a cada espécie de dano ${ }^{16}$.

Admite-se que a indenização deva buscar garantir a efetiva proteção da pessoa ${ }^{11}$. Danos extrapatrimoniais não são "ressarcíveis", no sentido etimológico de fazer desaparecer o dano (in+demne), pois o pagamento do quantum indenizatório não é capaz de eliminar o prejuízo causado, mas são "compensáveis", de maneira que a indenização possui natureza apenas satisfatória ou compensatória do dano, ao passo que danos materiais são suscetíveis de quantificação pecuniária, operando-se o ressarcimento do valor equivalente atribuído ao dano ${ }^{25}$. Os danos oriundos de um evento em discussão devem ser analisados em conjunto, para o efeito de se atribuir indenização por danos materiais, morais e estéticos ${ }^{16}$, como forma de se alcançar a reparação mais justa possível. O valor dessas indenizações tem sido fixado por arbitramento dos magistrados, com base no laudo pericial e de acordo com as circunstâncias do caso, já que não existe, ainda, dispositivo legal estabelecendo parâmetros objetivos a respeito ${ }^{8,20}$. Entrementes, por mais que haja uma indenização robusta para a lesão, é impossível o restabelecimento do estado anterior, o restitutio ad integrum $^{15}$. Ocorre que, ante a impossibilidade de retorno ao estado anterior da pessoa, a jurisprudência não tem outra alternativa a não ser a fixação de uma indenização pelos danos causados ${ }^{15}$.

Não obstante seja tido como dano permanente, no prejuízo estético é compatível o seu ressarcimento com o custo das intervenções de cirurgia plástica para sua correção ${ }^{1,7}$, incluídos na reparação do dano e na sua liquidação. Caso uma cirurgia possa implicar numa melhoria do dano no futuro, o lógico será valorizá-lo com uma certa atenuação no momento da elaboração do 
relatório pericial, do mesmo modo que a impossibilidade da correção constitui um fator que intensifica a importância do dano ${ }^{1}$. É de se destacar a discussão pericial neste sentido, já que pode ter havido minoração do dano no momento da avaliação pericial procedida a posteriori, ou mesmo jamais se poder recuperar o aspecto anterior, ante as características da lesão, ainda que o indivíduo queira se submeter à operação reparadora. Não se pode aceitar que o dano estético tenha lugar apenas quando se patenteia impossível corrigir o defeito resultante do acidente através de meios especializados. A doutrina mais moderna tem entendido que a correção, para afastar uma eventual indenização a título de dano estético, deve se dar de forma natural, conquanto ninguém pode ser obrigado a submeter-se a uma cirurgia, mesmo que seja para corrigir um dano. No tocante ao dano decorrente de lesão estética, uma reparação in natura é, de certa forma, improvável de ocorrer, uma vez que, por mais bem-sucedida que seja uma eventual cirurgia plástica reparadora, não é certa a restituição absoluta; excepcionalmente há reposição do status quo ante ${ }^{15,25}$. Ainda, em que pese possam existir artifícios de disfarce, não se elimina o dano ${ }^{13}$. Vale dizer também que há que se ponderar os possíveis riscos e resultados do tratamento ${ }^{7}$.

A valoração do dano estético é uma das tarefas mais complexas na avaliação pericial do dano corporal, pois decorre da confluência das perspectivas técnicas médico-legais e jurídicas na emissão do relatório. São imprescindíveis a apreciação e a análise qualificada de vários parâmetros específicos, com descrição detalhada para aclarar o juízo. Trata-se de analisar, única e exclusivamente, o grau de perda de atração do indivíduo, no contexto em que se situa, de modo independente de suas eventuais repercussões laborativas e diverso do prejuízo fisiológico que lhe porventura se constate, ainda que se deva ter em conta suas implicações no âmbito de sua vida social ${ }^{1,3}$. A quantificação do dano estético deve se dar separadamente, sem incorporação em outros parâmetros de dano, a fim de não o subestimar nem diluílo, uma vez que a desfiguração física pode ser ainda mais importante do que a funcional.

É de se salientar que devem ser avaliados, além das queixas e dos achados de exame físico atuais, aspectos relativos ao Estado Anterior do indivíduo, que são bastante relevantes no âmbito da apreciação a ser concretizada, observando-se antecedentes pessoais e registos clínicos. Discrepâncias eventualmente existentes entre a lesão sub judice e o dano apresentado merecem ser assinaladas e deve ser feita referência expressa a alterações encontradas que resultem de outra condição que porventura seja observada. Há que se sopesar se houve agravamento ou alteração para pior da harmonia física, dos traços e das formas do indivíduo, ou não, uma vez não se atribuindo ao evento em tela o quadro observado. Nestes casos, cabe maior discussão médico- pericial a respeito.

O dano estético engloba toda alteração morfológica do indivíduo que abrange as deformidades, deformações, marcas ou defeitos, ainda que mínimos, e que impliquem sob qualquer aspecto um afeiamento da vítima, consistindo numa simples lesão desgostante ou num permanente motivo de embaraçamento ou de depreciação, exercendo ou não influência sobre sua capacidade laborativa ${ }^{3-5,7,24,26}$. Tem-se como o dano aquilo que agride a pessoa nos seus sentimentos de autoestima, prejudicando a sua avaliação própria como indivíduo, o qual denigre a imagem que tem de si, não precisando estar exposto, ser externo, nem ser de grande monta, para que lhe traga um indizível sofrimento interno, psicológico, frustração e menosprezo ${ }^{27}$. Eis o montante subjetivo envolvido em sua caracterização, mostrandose imperiosa uma valoração pericial procedida de acordo com critérios médico-legais. Frisa-se aqui que é necessário que tenha havido uma piora em relação ao estado anterior da pessoa.

Merece destaque o método de identificação e de descrição do dano estético, assim como dos demais parâmetros de danos temporários e permanentes, que permita objetivar a impressão e o impacto de seu prejuízo, estimando, por meio de critérios, de uma forma evidente e acessível, os seus efeitos ${ }^{28}$. O trabalho do perito médico deve basear-se em critérios de referência e constituir ferramenta legal a ser devidamente interpretada e utilizada pelo julgador. Compete ao perito explicitar claramente em seu relatório a sua avaliação, justificando sua ponderação personalizada. Incumbe ao experto dar resposta concreta e adequada aos objetivos da perícia, procurando traduzir de modo fundamentado a complexidade da avaliação médica, para que todos os outros intervenientes no processo possam apreciar a interpretação exarada de modo individualizado, pretendendo, em última análise, que a autoridade judicial seja esclarecida, conforme suas necessidades.

Vários métodos têm sido propostos para quantificar o dano estético, e muito embora todos possam ser considerados ferramentas mais ou menos úteis para melhorar a qualidade das avaliações periciais, nenhum é universalmente aceito, não tendo sido validados de forma transcultural $1^{7,10,17,28-43}$. Diversos autores têm proposto métodos de avaliação do dano estético baseados nas dimensões das sequelas, em sua visibilidade a determinadas distâncias, em seus impactos pejorativos, em sistemas de pontuação, em fórmulas matemáticas, em escores, em jurisprudência, dentre outros ${ }^{1,8,10,20,21,42,43}$. De fato, de modo idôneo, há que se considerar precisamente todas essas possibilidades para a valoração da impressão e do impacto do prejuízo estético. Todavia, é imperioso que o perito proceda à análise do dano de modo amplo e relevante, baseada em exame físico completo - sem se limitar a valores indicativos, tabelas e cálculos, 
descrevendo de forma padronizada, pormenorizada, harmônica e particular, em atenção a critérios técnicos, o impacto assinalável do dano sobre o indivíduo, com vistas a se responder, justificar e esclarecer, adequadamente e de forma evidente, o julgador. $\mathrm{O}$ método descritivo demonstra a verdadeira natureza da alteração estética e seu significado, numa perspectiva estática e dinâmica, de maneira simples, evidenciando-se a intensidade do dano permanente para o indivíduo.

A valoração do Dano Estético é expressa através de uma escala quantitativa-descritiva de sete graus de gravidade crescente, proposta originalmente por Thierry e Nicourt ${ }^{1,3}$. O método descritivo é imprescindível, tendose em conta a história clínica e os achados de exame físico, bem como suas mais variadas repercussões pósconsolidação, sopesando-se o encadeamento anátomoclínico das lesões e sua categorização. É o meio que possui o perito para demonstrar a verdadeira natureza da alteração estética e a importância dos efeitos da perda de atração ${ }^{4}$, valorizando os elementos de forma conjunta que configuram o dano estético descrito, podendo-lhe atribuir um adjetivo ${ }^{1,3,8,20}$, da seguinte maneira: Muito ligeiro ou muito leve (1/7); Ligeiro ou leve (2/7); Moderado (3/7); Médio (4/7); Considerável (5/7); Importante ou grave (6/7); e Muito importante ou muito grave (7/7). Como sempre, é obrigatória a fundamentação da valoração deste dano, no capítulo do relatório médico-pericial referente à "discussão", para bem servir a Justiça, não bastando o perito tão unicamente recorrer à escala para traduzir sua avaliação. A necessidade assinalada de o experto respeitar metodologias periciais em vigor decorre do fato de apenas deste modo ser possível promover a harmonização de procedimentos e de avaliações para situações similares, respeitando-se o princípio da equidade. Esse método europeu de avaliação, em que destaca a Escola Portuguesa, tem sido utilizado no Instituto de Medicina Social e de Criminologia do Estado de São Paulo (IMESC), sopesando-se as normas jurídicas vigentes no Brasil.

Na ponderação deste parâmetro de dano, o perito deverá tomar em consideração múltiplos aspectos. A identificação e a descrição devem se concretizar no contexto individual da pessoa examinada, aplicandose as regras da arte médica, dado que danos estéticos similares podem ter repercussões substancialmente diferentes. Há que se ponderar fatores como idade, sexo, estado civil, profissão e condição social, bem como possibilidade de reparação com intervenção cirúrgica, uso de prótese, estado anterior, dentre outros ${ }^{1,3,4,10}$. Os aspectos característicos das lesões devem ser referidos especialmente quanto a seus tipos, localização, número, forma, dimensões, relevo, textura, simetria, coloração, exposição, perceptibilidade, amplitude, repercussão funcional, desfiguração e aviltância (tanto para quem as suporta quanto para quem as observa $)^{1,3,4,10}$. Ainda, deve ser perspectivado tanto numa vertente estática quanto numa vertente dinâmica, já que o dano estético pode ter uma dimensão diversa com a pessoa imóvel daquela observada nas múltiplas expressões do corpo e participações que podem ser concretizadas ao longo do dia-a-dia ${ }^{1,6}$. Tal como referido previamente, deve também o perito avaliar se o dano estético também interfere no exercício da atividade profissional do indivíduo, o que pode ocorrer em situações específicas.

No tocante à necessidade de ser a lesão localizada na aparência externa da vítima, não se tem entendido, atualmente, que a lesão seja visível em situações corriqueiras do cotidiano. Mesmo deformidades em áreas íntimas da pessoa, que dificilmente se exponham à vista de terceiros em situações sociais, caracterizam o dano estético, vez que a presença de alterações físicas, ainda que diminutas, têm sua presença conscientizada pelo portador e sabe este que em circunstâncias de maior intimidade com outras pessoas as mesmas aflorarão e tornar-se-ão visíveis $^{27}$. A deformidade não precisa ser vista a todo instante, sendo suficiente que exista no corpo, mesmo que resida em partes íntimas e nem sempre esteja em evidência ${ }^{12,13}$. Não se trata apenas de horripilantes lesões, mas de qualquer mudança ou transformação, bastando existir uma marca, um desequilíbrio entre o presente e o passado $^{13}$, o que gera ainda mais controvérsia.

Além de dados objetivos que devem ser explorados, há que se sopesarem fatores que encerram alguma subjetividade, como a percepção da própria pessoa em relação a seu dano corporal e a percepção de outrém ${ }^{1,6,7}$, como a tendência a despertar a atenção do observador e de se fixar o olhar, a resposta emocional que se segue ao visualizar o dano e a lembrança ou recordação que provoca por sua contemplação ${ }^{17,43}$, especialmente no que tange a mudanças impostas em suas situações de vida e emoções proporcionadas, podendo ter repercussões nos contextos físicos, econômicos, familiares, sociais e culturais, além das restrições pessoais que a pessoa venha a sofrer, distanciando-se do convívio social dado o seu aspecto. Vale dizer que situações semelhantes podem deter peculiaridades completamente distintas, devendo ser tratadas com a desigualdade que merecem ${ }^{15}$, levandose em consideração os fatores pessoais que individualizam cada indivíduo na sociedade ${ }^{13}$. Não se trata aqui de ferir o princípio da isonomia; a própria Constituição Federal assegura algumas formas de tratamento diferenciado com o fito de tornar iguais de fato os desiguais. Esta questão é relevante e tem importância prática porque alguém pode sofrer um menoscabo em sua integridade corporal e de tal lesão podem sobressair condições desfavoráveis, prejuízos morais e econômicos diversos de outrem. A desfiguração física tem de ser ponderada como um todo, no contexto de vida do indivíduo.

As dificuldades resultantes da tripla subjetividade de sua avaliação (por parte do indivíduo examinado, do 
perito e do julgador) ${ }^{1,10}$, atenuam-se mediante descrição minuciosa das sequelas, de forma orientada, rigorosa, clara, objetiva, pormenorizada, padronizada, sistematizada e compreensível, nomeadamente para leigos em medicina, bem como pela exibição de documentação fotográfica (mediante prévia autorização escrita da pessoa), para que o juiz as possa também apreciar e ver a forma como se enquadra a lesão no contexto corporal global do indivíduo, como complemento da observação pericial. Não é suficiente a imagem fotográfica isoladamente, por melhor que seja, para ilustrar um relatório pericial.

É bem sabido que qualquer pessoa pode opinar sobre a fealdade alheia e, inclusive, quantificá-la. Todavia, existem aspectos importantes que nos levam a pensar que deve ser o médico a avaliar o dano estético em questão, por sua capacidade para explorar o indivíduo, por poder, no exercício de seu trabalho, aceder visualmente a zonas danificadas, escondidas ou íntimas (que não podem ser contempladas pelo juiz de visu), bem como palpar as lesões, e por conhecer a evolução de um determinado estado (como ocorre com crianças, com cicatrizes anormais ou após intervenções cirúrgicas) ${ }^{1,44}$, ainda que seja certo que será o magistrado a decidir, em última análise, a valoração do dano. A abordagem pericial do dano estético deve ter em conta que a questão da desfiguração tem impactos pessoal e social que vão além da ciência médica; mesmo assim, por seus conhecimentos específicos, deve o experto elaborar relatório completo, fazendo referências explícitas dos elementos considerados, precisamente a fim de ser o magistrado capaz de verificar o grau do dano, formando sua convicção e ponderando-o, ao refletir sobre a apreciação técnica que o contemplou.

Nomeadamente em relação a processos de alegada má prática médica em cirurgias plásticas, em que se pleiteia indenização por dano estético, faz-se necessário esclarecer que a cirurgia plástica tem por objetivo a reconstituição de uma parte do corpo humano por razões médicas (cirurgia reparadora) ou meramente estéticas (cirurgia embelezadora). A cirurgia reparadora, para os efeitos jurídicos, é realizada fundamentalmente para restaurar tecidos, reconstruir órgãos, repor membros e recuperar funções, tendo a função de corrigir danos físicos e deformações (congênitos ou adquiridos) ligados à saúde do indivíduo, deixando a perfeição estética em segundo plano, impondo obrigação de meio, em que não há compromisso de resultado. A cirurgia estética stricto sensu é aquela destinada exclusivamente ao embelezamento da pessoa, visando correção, melhora da aparência e perfeição estética, e que não tem reflexo sobre sua saúde, impondo, juridicamente, obrigação de resultado, pois deve corresponder ao contratado e esperado pelo paciente. Especialmente na valoração do dano estético que pode advir em ambos os casos, deve o perito discorrer também sobre cicatrização tecidual e sobre resultados de fato possíveis que podem ir tanto ao encontro quanto de encontro às expectativas do indivíduo, deixando claro ao julgador se houve, ou não, sob a óptica médica, sucesso no procedimento, em suas mais variadas formas. É essencial que se consigne que toda intervenção operatória implica na ocorrência de uma cicatriz, tendo em conta o processo de reparação tecidual normal, não se admitindo que seja, de per se, um mau resultado decorrente de falha técnica. Em que pese poder ser caracterizada a cicatriz de uma cirurgia plástica como dano estético, sob a óptica médico-legal, sua valoração deve abarcar também essas noções e deve ser sobremaneira fundamentada. Não obstante, é imperioso que se registre que o achado pós-operatório pode não traduzir dano estético, tendo-se o resultado de acordo com o esperado, não se constatando alteração pejorativa da imagem do indivíduo ${ }^{42}$, o que deve ser amplamente discutido no corpo do laudo.

\section{CONSIDERAÇÕES FINAIS}

É de se salientar que a necessidade de se seguir método de avalição homogêneo e simples, uma vez estabelecidos parâmetros de valoração, é de suma importância para que os peritos e magistrados coincidam em suas análises em casos similares. Há que atender aos parâmetros de valoração, levando em conta também as circunstâncias pessoais da vítima. É inegável que há uma constelação de fatores socioculturais que determinam a cada tempo e a cada lugar o que é belo e o que é feio, de modo eminentemente subjetivo. Cada pessoa tem uma percepção diferente da mesma realidade, porque a realidade externa se converte, consoante processos emocionais próprios, em realidade individual. Daí o perito necessitar traduzir o impacto psicológico do dano para a pessoa em especial.

A quantificação pericial do dano estético deve ser realizada por meio de critérios que estimem, de uma forma evidente e de fácil compreensão para autoridades judiciais, os efeitos que a alteração do aspecto exterior do indivíduo provoca a si mesmo e a outrem ${ }^{1,4,6,7,11}$. O perito deve se encontrar atualizado sobre as abordagens existentes do dano estético, realizar uma descrição pormenorizada das lesões, bem como efetuar uma avaliação completa da pessoa à autoridade requisitante. Em sua avaliação detalhada, o perito deve considerar o sentimento da pessoa relativamente a esse dano. $\mathrm{O}$ método de utilização de escala de sete graus de gravidade crescente para valoração do dano estético abrange de forma global todo o dano estético descrito, tendo em conta seus elementos de forma conjunta, baseando-se nos critérios abordados, em que pese sejam alguns empíricos, merecendo rigor e justificativa ao se atribuir um número e/ou adjetivo, sendo certo que não há como se atribuir unicamente valores ao que de principio e por definição 
não tem tradução matemática.

Vale ressaltar que a quantificação objetiva do dano estético - por pontos, porcentagens e tabelas -, ainda que tenha seu valor e potencial para oferecer maior objetividade na valoração do prejuízo estético, pode não traduzir a gravidade do dano estético e o impacto sobre as mais variadas situações de vida da pessoa, visto que não só restringe a atuação do experto, mas também pode implicar eventualmente em menor detalhamento de suas características e até induzir menor exploração contextual do dano, deixando-se efetivamente de discorrer a seu respeito de modo suficiente, dentro da realidade do examinado, sendo certo que há imensa subjetividade interpretativa na apreciação do comprometimento estético adquirido. Numa avaliação técnica em que se pretende obter Justiça, não se pode coarctar, de forma alguma, a liberdade técnico-científica dos peritos, nem limitar sua plena manifestação, sopesando-se suas elevada experiência e capacidades, o que enriquece o exercício da atividade pericial médico-legal ${ }^{1}$. De fato, quem avalia cientificamente e quem julga determinando o montante indenizatório deve considerar fundamentalmente a repercussão do dano estético para aquele que o sofre, a fim de que se tenha a real dimensão do prejuízo estético, o qual guarda subjetividade em sua origem.

A escala quantitativa-descritiva é de grande valia na avaliação do dano estético, visto que pontua aspectos objetivos e permite a unificação de diferentes critérios, uma vez detalhadas as características da sequela e exploradas suas repercussões nas circunstâncias de vida da pessoa, o que permite conhecer a percepção do dano estético para si e para os outros, conforme a relevância de seu alcance afetivo. A devida ponderação pode escapar do conhecimento médico, mas é imperioso que o perito se pronuncie, ante critérios técnicos e conforme método estabelecido, e ofereça detalhamento dos elementos que constituem o prejuízo estético ao julgador, que, com mais arbítrio, poderá mensurá-lo e repará-lo.

Leal LPFF, Silva ER, Spina VPL, Borracini JA, Panza FT. Medical-Examiner Assessment of Aesthetic Damages. Saúde, Ética \& Justiça. 2017;22(1):41-9.

\begin{abstract}
The expert assessment of damage constitutes a technical activity, to which apply the rules of the Medical Art, within the context of the law. The medical report must be comprehensive and allow understanding the actual situation of the individual. The evaluation of the expert should ensure clarification of the judgment, thus contributing to justice. It is fundamental that personal injury is identified, described, and valued according to a rigorous scientific method. This article takes into account the experience of the Institute of Social Medicine and Criminology of the State of São Paulo (IMESC) to discuss Aesthetic Damage, both in its diagnosis and in its assessment within the Brazilian legal framework. The assessment method employed is based on a quantitative-descriptive scale, aiming for harmonization in its consideration, within the general principle of integral reparation of damages, in a contextualized and grounded manner.
\end{abstract}

KEY-WORDS: Expert Testimony; Damage Assessment Methodologies; Esthetics; Forensic Medicine; Compensation and Redress.

\title{
REFERÊNCIAS
}

1. Magalhães T, Corte-Real F, Vieira DN. O relatório pericial de avaliação do dano corporal em Direito Civil. In: Vieira DN, Quintero JA, coord. Aspectos práticos da avaliação do dano corporal em Direito Civil. Brasília: Caixa Seguros e Imprensa da Universidade de Coimbra; 2008.

2. Leal LPFF, Milagres A. A importância do laudo pericial médico na formação do entendimento do juízo: análise de casos de suposta má prática médica em cirurgia geral. Saúde, Ética \& Justiça. 2012;17(2):82-90. DOI: http://dx.doi. org/10.11606/issn.2317-2770.v17i2p82-90

3. Silva BR, Carvalho CM, Bouchardet FCH, Silva WFM, Santos WB. Avaliação do dano corporal pós-traumático: metodologia europeia aplicada ao contexto brasileiro. Belo Horizonte: Mazza; 2010.

4. Criado del Río MT. Valoración médico-legal del daño a la persona. Tomo II - Doctrina médico-legal de valoración de daños personales. Madrid: Colex; 2010. p.375-432.

5. Cueto $\mathrm{CH}$. Valoración médica del daño corporal: guia práctica para la exploración y evaluación de lesionados. $2^{\mathrm{a}}$ ed. Barcelona: Masson; 2001.
6. Vieira DN. A missão de avaliação do dano corporal em Direito Civil. Sub Judice, Just e Soc. 2000;17:23-30.

7. Cobo Plana JA. La valoración del daños a la personas por accidentes de tráfico. Barcelona: Editorial Bosch; 2010. p.635-706.

8. Bouchardet FCH, Vieira SLG, Miranda GE, Fernandes MM, Vieira DN, Silva R. Valoração do dano estético nos acórdãos do Tribunal de Justiça de Minas Gerais. ROBRAC. 2013;22(63):116-9.

9. Alonso Santos J. La valoración del perjuicio estético. Cuad Med For. 1998;14:7-20.

10. Valiente AR, Sasot AV. Revisión y crítica de la valoración del daño estético. Propuesta de un nuevo baremo. Cuad Med Forense. 2014;20(1):26-35.

11. Lopez TA. O dano estético: responsabilidade civil. $3^{\text {a }}$ ed. São Paulo: Editora Revista dos Tribunais; 2004.

12. Espinoza MA. Dano estético e suas particularidades. Revista Âmbito Jurídico [Internet]. 2015 [acesso em 2017 abr. 15]; Ano XVIII, n. 143. Disponível em: http://ambitojuridico.com.br/site/index.php/?n link=revista artigos 
leitura\&artigo id $=16626 \&$ revista caderno $=7$

13. Santos CFB. O Dano Estético. Via JUS [Internet]. s/d [acesso em 2017 abr. 15]. Disponível em: http://www.viajus.com.br/ viajus.php? pagina $=$ artigos\&id $=4478 \& i d$ AreaSel $=2 \&$ see $A r$ $t=y e s$

14. Barros FLM. O dano estético e a responsabilização civil. Revista Jus Navigandi [Internet]. 2001 [acesso em 2017 abr. 15]; ano 6, n. 49. Disponível em: https://jus.com.br/ artigos $/ 1870$

15. Almeida MCLD. A parametrização da indenização por dano estético. Revista Âmbito Jurídico [Internet]. 2014 [acesso em 2017 abr. 15]; Ano XVII, n. 120. Disponível em: http:// www.ambito-juridico.com.br/site/?n_link=revista_artigos leitura\&artigo $\mathrm{id}=14162$

16. Oliva BK. Dano estético: Autonomia e cumulação na responsabilidade civil. Revista Âmbito Jurídico [Internet]. 2009 [acesso em 2017 abr. 15]; Ano XII, n. 70. Disponível em: http://www.ambito-juridico.com.br/site/index.php?n link $=\% 20$ revista \%20artigos leitura\&artigo id $=6920$

17. Fernandes MM, Cobo-Plana JA, Bouchardet FCH, Michel-Crosato E, Oliveira RN. Validação de instrumento para análise do dano estético no Brasil. Saúde Debate. 2016;40(108):118-30. DOI: http://dx.doi.org/10.1590/01031104-20161080010

18. Constituição da República Federativa do Brasil. $13^{\mathrm{a}}$ ed. São Paulo: Revista dos Tribunais; 2008

19. Brasil. Presidência da República, Casa Civil, Subchefia para Assuntos Jurídicos. Lei $\mathrm{n}^{\mathrm{o}} 10.406$, de 10 de janeiro de 2002. Institui o Código Civil [Internet]. Brasília, DF; 2006. Disponível em: http://www.planalto.gov.br/ccivil_03/ leis/2002/L10406.htm

20. Fernandes MM, Bouchardet FCH, Tavares GSV, Daruge Junior E, Paranhos LR. Aspectos odontolegais relacionados ao dano estético nos processos julgados pelo TJ/RS. Odonto. 2012;20(40):7-12. DOI: http://dx.doi.org/10.15603/21761000/odonto.v20n40p7-12

21. Fernandes MM, Bouchardet FCH, Delwig F, Tinoco RLR, Daruge Jr E, Oliveira RN. Valoração do dano estético odontológico utilizando três métodos: relato de caso pericial civil. Rev Bras Odontolol Leg RBOL. 2016;3(1):84-94. DOI: http://dx.doi.org/10.21117/rbol.v3i1.48

22. Oliveira SG. Indenizações por acidente do trabalho ou doença ocupacional. $6^{\text {a }}$ ed. São Paulo: Ltr; 2011.

23. Brasil. Tribunal Superior de Justiça. Súmula 387. É lícita a cumulação das indenizações de dano estético e dano moral [Internet]. Brasília, DF; 2009. Disponível em: https:// ww2.stj.jus.br/docs internet/revista/eletronica/stj-revistasumulas-2013_35_capSumula387.pdf

24. Gonçalves CR. Responsabilidade Civil. $16^{\text {a }}$ ed. São Paulo: Saraiva; 2015.

25. Bonatto FM. A quantificação da indenização por dano extrapatrimonial: análise dos critérios jurisprudenciais na determinação do quantum debeatur. Direito \& Justiça. 2011;37(2):136-54.

26. Diniz MH. Curso de direito civil brasileiro. Vol 7 Responsabilidade civil. 30a ed. São Paulo: Saraiva; 2016.

27. Souza NTC. O dano estético na atividade do médico [CDROM Júris Síntese]. Porto Alegre: Editora Síntese; 2001.

28. Bouchardet FHC, Criado del Río MT. Propuesta de una
Guía para la Valoración Médico-Legal de la Alteración Estética: Daño Estético/Deformidad. Revista Portuguesa do Dano Corporal. 2010;(21):119-30. DOI: http://dx.doi. org/10.14195/1647-8630_21 6

29. Pérez Pineda B, García-Blázquez M. Curso práctico de manejo y aplicación de la Orden de 5 de marzo de 1991. Granada: Comares; 1994.

30. Hernández Cueto C. Breve revisión crítica del actual sistema de valoración médica de los daños corporales en España. DS. 1995;3:205-24.

31. Sánchez Fuente R. Descripción y valoración del perjuicio estético. In: IV Curso de Especialistas Universitarios en Valoración del Daño Corporal. Valladolid: Universidad de Valladolid; 1996.

32. Rodríguez I, Hinojal Fonseca R. La valoración del perjuicio estético en un sentido más objetivo para su aplicación a la Ley 30/1995. In: $2^{\circ}$ Congreso Hispano-Luso de Valoración del Daño Corporal. Madrid: Sociedad Española de Valoración del Daño Corporal; 1998.

33. Alonso Santos J. El daño estético. In: III Jornadas Andaluzas sobre valoración del daño corporal. Sevilla: Asociación Andaluza de Médicos Forenses; 1998.

34. Hinojal Fonseca R. La valoración del perjuicio estético para su aplicación a la ley 30/1995. La Ley: Revista jurídica española de doctrina, jurisprudência y bibliografía. 1999;3:2098-106.

35. Bermúdez J. Valoración del daño estético por cicatrices. Cuadernos de Valoración. 2004;3:35-42.

36. Aso Escario J, Cobo Plana JA. Valoración de las lesiones causadas a las personas en accidentes de circulación a partir de la Ley 34/03. $3^{\mathrm{a}}$ ed. Barcelona: Masson; 2006.

37. Carol i Joval J. Valoración del daño corporal en accidentes de tráfico y pólizas de seguros. Barcelona: Atelier Libros, 2006.

38. Asociación Argentina de Compañías de Seguros (AACS). Baremo AACS 2006. Versión 1.0. Buenos Aires: Asociación Argentina de Compañías de Seguros; 2006.

39. Borobia Fernandez C. Valoración del daño corporal: Legislación, metodología y prueba pericial médica. Barcelona: Elsevier-Masson; 2007.

40. Pérez Pineda B, García-Básquez M. Nuevo Manual de valoración y baremación del daño corporal. $15^{\mathrm{a}}$ ed. Madrid: Editorial Comares; 2007.

41. Puig Bausili L, Pujol Robinat A, Corrons Perramón J, Medallo Muñiz J. Valoración del daño estético en las amputaciones. Rev Esp Med Legal. 2011;37(3):90-6. DOI: http://dx.doi. org/10.1016/S0377-4732(11)70070-0

42. Fernandes MM, Baldasso RP, Sakaguti N, Bouchardet FCH, Plana JAC, Oliveira RN. Como justificar a ausência de dano estético? Relato de perícia civil odontológica. Rev Bras Odontol Leg RBOL. 2017;4(1):114-21

43. Bourchardet FCH, Cobo Plana JA. Utilización del método "AIPE" en la valoración del perjuicio estético y su aplicación en la legislación Brasileña civil y penal. Revista Portuguesa do Dano Corporal. 2011;22:167-81.

44. Brasil. Presidência da República, Casa Civil, Subchefia para Assuntos Jurídicos. Lei $\mathrm{n}^{\circ}$ 12.842, de 10 de julho de 2013. Dispõe sobre o exercício da Medicina [Internet]. Brasília, DF; 2013. Disponível em: http://www.planalto.gov.br/ ccivil 03/ ato2011-2014/2013/lei/112842.htm 